\title{
Netmums: a phase II randomized controlled trial of a guided Internet behavioural activation treatment for postpartum depression
}

\author{
H. A. O'Mahen ${ }^{1 *}$, D. A. Richards ${ }^{2}$, J. Woodford ${ }^{1}$, E. Wilkinson ${ }^{3}$, J. McGinley ${ }^{4}$, R. S. Taylor ${ }^{5}$ \\ and F. C. Warren ${ }^{5}$ \\ ${ }^{1}$ Mood Disorders Centre, University of Exeter, Washington Singer Building, Exeter, UK \\ ${ }^{2}$ University of Exeter Medical School, Washington Singer Building, Exeter, UK \\ ${ }^{3}$ Academic Unit of Child and Adolescent Psychiatry, Imperial College, St Mary's Campus, Norfolk Place, London UK \\ ${ }^{4}$ Netmums.com, Marylebone Business Centre, London, UK \\ ${ }^{5}$ University of Exeter Medical School, Veysey Building, Exeter, UK
}

Background. Despite the high prevalence of postnatal depression (PND), few women seek help. Internet interventions may overcome many of the barriers to PND treatment use. We report a phase II evaluation of a 12-session, modular, guided Internet behavioural activation (BA) treatment modified to address postnatal-specific concerns [Netmums Helping With Depression (NetmumsHWD)].

Method. To assess feasibility, we measured recruitment and attrition to the trial and examined telephone session support and treatment adherence. We investigated sociodemographic and psychological predictors of treatment adherence. Effectiveness outcomes were estimated with the Edinburgh Postnatal Depression Scale (EPDS), Generalized Anxiety Disorder-7, Work and Social Adjustment Scale, Postnatal Bonding Questionnaire, and Social Provisions Scale.

Results. A total of 249 women were recruited via a UK parenting site, Netmums.com. A total of 83 women meeting DSM-IV criteria for major depressive disorder were randomized to NetmumsHWD $(n=41)$ or treatment-as-usual (TAU; $n=42)$. Of the 83 women, $71(86 \%)$ completed the EPDS at post-treatment, and $71 \%(59 / 83)$ at the 6-month follow-up. Women completed an average of eight out of 12 telephone support sessions and five out of 12 modules. Working women and those with less support completed fewer modules. There was a large effect size favouring women who received NetmumsHWD on depression, work and social impairment, and anxiety scores at post-treatment compared with women in the TAU group, and a large effect size on depression at 6 months post-treatment. There were small effect sizes for postnatal bonding and perceived social support.

Conclusions. A supported, modular, Internet BA programme can be feasibly delivered to postpartum women, offering promise to improve depression, anxiety and functioning.

Received 15 February 2013; Revised 9 July 2013; Accepted 21 July 2013; First published online 9 October 2013

Key words: Anxiety, behavioural activation, bonding, cognitive behavioural therapy, depression, Internet interventions, postnatal depression.

\section{Introduction}

The postpartum period is a critical developmental period for mothers and infants, during which an estimated $13 \%$ of women suffer from postpartum depression (Gavin et al. 2005). The impact of postpartum depression, which affects both the mother and infant, is significant. The effects of these early problems are profound, with longitudinal studies demonstrating that postpartum depression has long-term negative cognitive, social and emotional implications for the child (Pawlby et al. 2008; Murray et al. 2010). Post-

\footnotetext{
* Address for correspondence: H. A. O'Mahen, Mood Disorders Centre, University of Exeter, Washington Singer Building, Exeter EX4 4QG, UK.

(Email: ho215@ex.ac.uk)
}

partum depression recognition amongst health professionals is poor (Murray et al. 2004) and help-seeking amongst postpartum women remains low (17-25\%; Buist et al. 2005). In recognition of this, both USA- and UK-based guidelines recommend prioritizing prompt intervention for postpartum depression (National Institute for Health and Clinical Excellence, 2007; National Research Council and Institute of Medicine, 2009), however, women face a number of factors that impede their ability to receive appropriate treatment.

The postpartum period presents specific barriers to accessing appropriate depression treatment. Women report a preference for psychotherapy over antidepressants, particularly when they are breastfeeding (Dennis \& Chung-Lee, 2006). The postpartum period presents unique barriers to office-based treatment, and includes specific treatment-related needs

The online version of this article is published within an Open Access environment subject to the conditions of the Creative Commons Attribution licence <http://creativecommons.org/licenses/by/3.0/>. 
(Dennis \& Chung-Lee, 2006; O’Mahen \& Flynn, 2008; Goodman, 2009). Mothers of infants and young children report struggles with transportation and childcare (Goodman, 2009), while variable infant feeding and napping schedules can interfere with the ability of women to attend regularly scheduled appointments. Despite stigma-reduction campaigns aimed at improving awareness of postpartum depression (e.g. Crisp et al. 2005), women continue to report perceived stigma about postpartum depression (O'Mahen \& Flynn 2008; Goodman, 2009). A significant minority of women also report fears that their children will be 'taken away' if health providers discover they suffer from depression (Dennis \& Chung-Lee, 2006). In recent phase I (Craig et al. 2008) development work we have conducted, mothers experiencing postnatal depression (PND) also expressed concerns about treatments lacking content specific to the postpartum period ( $\mathrm{O}^{\prime}$ Mahen et al. $2012,2013 a$ ). These included: difficulties in finding normalizing information about mothering; problems in accessing and utilizing support from others; maternal sleep difficulties associated with infant sleep schedules and problems adjusting to and managing the busy schedule of an infant balanced against other valued tasks. Finally, empirically supported psychotherapies are not equivalently distributed geographically, resulting in inequities in access to appropriate treatment (Payne \& Myhr, 2010).

Internet delivery systems offer an alternative, promising approach that may circumvent many of the difficulties of face-to-face delivery techniques (Kohn et al. 2004). Offering therapy online could provide women with the flexibility of receiving treatment at a time and place convenient for them, avoid the time and economic costs associated with providing home-based therapy, and reduce concerns about confidentiality and delivery in home and public spaces. Internet-based interventions also provide a level of anonymity not possible with face-to-face therapy (e.g. distance-based, supporter does not see client's face) (Beattie et al. 2009), potentially overcoming women's concerns about stigma (Dennis \& Chung-Lee, 2006). In support of this, a recent investigation of online screening for PND demonstrated that mothers were more likely to report sensitive information regarding their mood over the Internet (Le et al. 2009). Lastly, computerized interventions require less overall therapist contact time, thereby reducing costs and improving treatment accessibility (Andrews et al. 2010).

\section{Why create a new online treatment for postpartum depression?}

Online cognitive behavioural therapy (CBT) for depression has been demonstrated in a number of randomized controlled trials (e.g. Christensen et al. 2004; Warmerdam et al. 2008; Meyer et al. 2009; Perini et al. 2009) and systematic reviews (e.g. Spek et al. 2007; Kaltenthaler et al. 2008). A meta-analysis of both supported and unsupported online interventions for major depression (Andrews et al. 2010) found moderate to large levels of effectiveness [effect size $^{1}+0.78,95 \%$ confidence interval (CI) 0.59-0.96].

However, recent literature suggests that online CBT programmes cannot always be seamlessly individualized for specific treatment conditions, thereby reducing the acceptability of programmes to individuals with particular conditions (Hind et al. 2009). Because our phase I work (O'Mahen et al. 2012) suggested that women suffering from postpartum depression required specific treatment adaptations, we developed an online behavioural activation (BA) treatment that was specifically adapted to the concerns of postnatal women. BA is a straightforward and parsimonious approach that contains a functional analytical approach to the behavioural components of CBT, without using the cognitive components, and has been shown to be as effective as traditional CBT (Jacobson et al. 2001; Dimidjian et al. 2006).

We previously tested the feasibility and initial efficacy of an 11-session minimal support version of online BA modified for PND (O'Mahen et al. 2013b). Although there were small to moderate treatment effect sizes for women who were trial adherent, there were high rates of attrition $(63 \%)$. Women in the trial reported difficulties keeping up with the materials and struggling to individualize the materials. We modified the treatment materials to take a modular approach, and added a guided support component in order to improve treatment understanding and adherence rates (Cuijpers et al. 2010).

In accord with the UK Medical Research Council framework for complex interventions, we report the results of the subsequent phase II (Craig et al. 2008) randomized controlled trial of the guided BA-based modular computerized treatment programme that we developed for postpartum depression (Netmums Helping With Depression; NetmumsHWD), compared with treatment-as-usual (TAU). The aims of the study were: (1) to establish recruitment and trial adherence rates; (2) to determine treatment adherence and predictors of modules and telephone sessions; (3) to assess the preliminary effectiveness of NetmumsHWD on depressive and anxious symptoms, work and social impairment, perceived support, and maternal selfreported bonding with her infant in order to help inform future sample size calculations; and (4) to

+ The notes appear after the main text. 
gather data on health care utilization at baseline and at post-treatment in preparation for a health economic assessment.

\section{Method}

\section{Recruitment}

We recruited participants between October 2011 and February 2012 by advertisements on website banners, 'new "Helping with Depression" treatment study', on the UK Netmums parenting website front page and on their PND chat room page (www.netmums.co.uk), through the Netmums' newsletter, via emails to women who had posted on the PND chat room in the previous 12 months, and via the Netmums Twitter and Facebook sites. Interested participants provided electronic informed consent, and then accessed information on the Netmums website describing the treatment, eligibility and randomization procedures. Consenting women filled in screening questionnaires online, including the Edinburgh Postnatal Depression Scale (EPDS), to assess their potential eligibility for the trial.

\section{Participants}

Women completing the screening battery who were aged over 18 years, had given birth to a live baby in the last year, scored greater than 12 on the EPDS, did not experience substance abuse, psychosis, and spoke English were potentially eligible for the study. We contacted potentially eligible women via telephone to complete a diagnostic clinical assessment. Women who met International Classification of Diseases, 10th Revision (ICD-10) criteria for major depressive disorder (MDD) were eligible for the study.

\section{Randomization and allocation}

Eligible and consenting women were randomized to receive either NetmumsHWD or TAU, minimized on depression severity (EPDS $\geqslant 13$ ) and whether or not they were currently receiving pharmacological treatment. The minimization algorithm included a stochastic element to inform the allocation process and was administered remotely using a computer-generated code to ensure concealment. Randomization occurred online; eligible women were sent an electronic link to a webpage where they could learn their randomization assignment.

\section{Interventions}

\section{Treatment (NetmumsHWD)}

Following a previous trial (O'Mahen et al. 2013b) which developed the BA treatment from qualitative work with depressed postnatal women (O'Mahen et al. 2012), a core group of stakeholders (specialist health visitor, Netmums peer supporter, and two service users) worked with the researchers to modify the treatment content and presentation to fit with previous trial participants' feedback. The modified 12-session treatment course consisted of a core BA module (five sessions) and a relapse prevention session. Women also chose two optional modules from a list of a possible six (see Table 1 for a description of the treatment). All modules followed the BA functional analytical framework (Addis \& Martell, 2004). The content included interactive exercises paired with extensive worked examples. Sessions could be supplemented by a cache of resources on the Netmums site, including their 'meet a mum' feature, which allowed women to connect with other women in their local area. Women also had access to a chat room that was moderated by peer supporters and was open only to women in the treatment. Presentation of the website was simplified to ensure that a wide range of users with varying technical skill could use the website without training.

Women received weekly phone call support from mental health workers with undergraduate degrees and 1 year of further clinical qualification in psychological therapies under the UK Improving Access to Psychological Therapies (IAPT) training scheme. Supporters, who had previously been trained in 'lowintensity' (monitoring and scheduling) BA, received 5 days of training in the 'high-intensity' (functional analysis-based) perinatal-specific BA approach used in the treatment (Dimidjian et al. 2006; $\mathrm{O}^{\prime}$ Mahen et al. 2013b). Training involved a mix of didactics and roleplay around conducting functional analysis in perinatal-specific domains with the chief investigator (H.O.), a clinical psychologist with specialty expertise in BA and perinatal depression, and an IAPT trainer (J.W.). Supporters provided telephone sessions of 20-30 min that focused on answering questions about treatment material and working through barriers to treatment implementation. Supporters had computer access to women's completed exercises. They followed sessional support guides that outlined key topic areas to cover for each session (e.g. functional analysis of infant-mother play, breaking down goals, brainstorming solutions). Sessions were audio-recorded and $20 \%$ of the sessions were monitored weekly for adherence to the sessional guides. Adherence was monitored and addressed in weekly 1-hour supervision with H.O., the chief investigator. Women who missed sessions were actively followed up by supporters using telephone calls, emails and text messages to reschedule appointments. 
Table 1. Description of session content

\begin{tabular}{ll}
\hline Module title & Session title \\
\hline $\begin{array}{ll}\text { Core module } \\
\text { Session 1 }\end{array}$ & Behavioural activation \\
Session 2 & Understanding depression and the mood-activity link \\
Session 3 & How did I get here? \\
Session 4 & 'Help! I want to get better!' Moving out of depression \\
Session 5 & When the going gets tough. What to do \\
Optional modules & Getting the balance right. Being a mother and a perso \\
Optional module 1 & Being a good enough mother \\
Session 1 & Introduction \\
Session 1, topics 1-3 & Topic 1: Attachment and bonding with my baby. \\
& Understanding \\
& TRAPs \\
& Topic 2: Colicky, fussy baby \\
Session 2, topics 1-3 & Topic 3: Feeding difficulties \\
& Getting back on TRAC
\end{tabular}

Session content

Monitoring mood and activity

Introduction to avoidance and functional analysis (TRAP)

Introduction to planning alternative meaningful behaviour (TRAC)

Contingency planning. Breaking down tasks and problem-solving

Achieving TRACs in creative and realistic ways. Prioritizing

Introduction to topic. Mother could choose one of three parenting topics to focus on within this module Functional analysis of:

Topic 1: play with baby

Topic 2: colicky, fussing situations with baby, including mother's reactions and coping Topic 3: feeding difficulties

Exploring alternative specific behaviours in each topic specific area. (e.g. play behaviours, maternal self-soothing responses to colic). Incorporate specific Netmums tools where appropriate (chat rooms to brainstorm ideas, ideas for managing colic)

Session 3, topics 1-3 Building on successes and overcoming obstacles Optional module 2

Session 1 Support and communication module

Don't go it alone. Getting the support you need

Session 2

Session 3

Moving on to more difficult conversations

Building a lifeline with other mothers

Session $4 \quad$ Continuing to build a lifeline with other mothers

Optional module $3 \quad$ Changing roles and relationships (transitions)

Session 1

Introduction

Session 1, topics 1-4 Topic 1: Work

Topic 2: Friendship and social independence Topic 3: Relationship with partner

Topic 4: Always struggled! Was never a 'good'

housewife and now I'm not a good mother either

Session 2, topics 1-4 Overcoming barriers, Building on TRACs

Session 3, topics 1-4 Managing conflict between long-term goals. Linking short-term goals with restructured long-term goals

Identifying specific difficult conversational patterns. Functional analysis of conversation. Picking specific conversations to address. Identifying alternative options (TRAC) with negative conversations Building greater depth with more conversational TRACs

Improving communication and relationships with other mothers

Identifying conversation TRAPs from previous week. Breaking down problem conversations. Instituting new TRACs. Developing new TRAC conversation goals

Introduce topic of transition and way it makes an impact on goals and mood. Identify at least one topic of focus

Identify reinforcers in important goals pre-baby.

Identify current missing reinforcers (e.g. enjoyed a sense of accomplishment and recognition at work, missing this now). Identify opportunities to implement reinforcers in context of current life within TRAC model

Problem-solving barriers to TRAC, building on new TRACs in same domain when successful Identifying goal conflict (e.g. work and family). Brainstorming individual specific solutions. Linking short-term goals to long-term goal solutions 

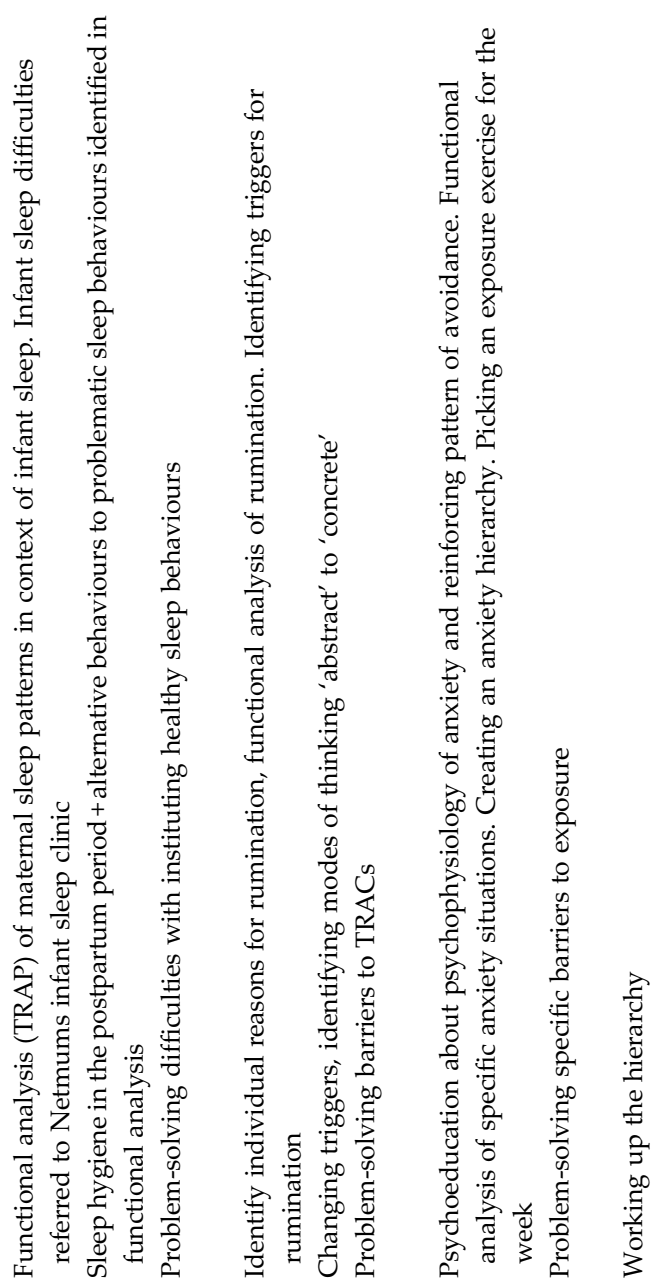

\section{Control (TAU)}

The TAU condition was allowed to vary according to usual practice. Women in both groups had access to Netmums' general depression chat room throughout the course of the study. This chat room is moderated by health visitors and parent supporters who provide email/chat room posting support and advice for depression.

\section{Measurement}

\section{Recruitment and attrition}

We collected data on the numbers of potential and actual participants presenting at each stage of the recruitment and follow-up process to quantify the flow of participants through the trial and assess the feasibility, and recruitment and retention yield of our procedures. Data were collected online and via telephone.

\section{Treatment adherence and predictors of adherence}

We measured the numbers of modules viewed by women, modules completed, and the numbers of telephone support sessions received by participants. We collected demographic data at baseline on income level, work and relationship status, education qualifications, and number of children to assess the moderating effects of these variables.

\section{Depressive symptoms}

We assessed participants' mood symptoms at baseline, 17 weeks post-treatment, and 6 months post-treatment with the EPDS (Cox et al. 1987), a widely used, reliable and valid self-report 10 -item scale measuring symptoms of PND (range 0-30).

\section{Anxiety}

We used the Generalized Anxiety Disorder Scale (GAD-7), a seven-item measure, to assess levels of general anxiety (Spitzer et al. 2006). The GAD-7 has been demonstrated to have good validity and reliability (Löwe et al. 2008) and accurately predicts the presence of anxiety disorders (Swinson, 2006).

\section{Work and social impairment}

We measured functional impairment with the Work and Social Adjustment Scale (WASAS; Mundt et al. 2002), a five-item measure that has demonstrated very good to excellent reliability and validity (Mundt et al. 2002). The WASAS has been used with women suffering from postpartum depression (Reay et al. 2006). 
Social support

We assessed perceived availability of support with the 24-item Social Provision Scale (SPS; Cutrona \& Russell, 1987). The SPS has good reliability and validity and has been used widely in studies of social support. Higher scores represent greater perceived support.

\section{Postnatal bonding}

We used the 25-item Postnatal Bonding Questionnaire (PBQ; Brockington et al. 2001) to assess parental perceptions of the relationship with the infant. The PBQ has adequate internal reliability and validity and is sensitive to changes in treatment. Higher scores represent greater reported difficulties in bonding.

\section{Health service utilization}

We used the Adult Service Use Schedule (AD-SUS), an instrument designed on the basis of previous studies of adult mental health populations (Byford et al. 2003). The AD-SUS asks recipients for the number and length of contacts with various services and professionals relevant to the disease of interest over the previous 3 months. We further adapted the AD-SUS to include services utilized by mothers of young infants.

\section{Sample size}

Our primary intent was to estimate recruitment, retention and adherence levels for the intervention, and to estimate standard deviations for the primary outcome, the EPDS, to inform a sample size calculation for a future fully powered trial. We aimed to randomize approximately 80 participants in total. With an estimated $20 \%$ attrition rate, a sample size of 80 allowed us to estimate the attrition rate with a $95 \%$ CI width of approximately 20 percentile points. Further, with an estimated $20 \%$ attrition rate, a sample size of 64 is sufficient for estimation of retention and adherence levels and standard deviations of outcome variables (Julious, 2005).

\section{Statistical analysis}

We analysed recruitment and retention data using counts of participants at each stage in recruitment and retention, expressed as a percentage of the total number of participants initially indicating interest and in relation to the preceding step in recruitment. We report means and standard deviations for treatment adherence. We used correlation, $t$ tests, and Goodman and Kruskal lambda to analyse predictors of treatment adherence.

We analysed all clinical outcome data on an intention-to-treat basis. We examined demographic variables to assess pre-treatment balance across the groups and undertook descriptive analysis of baseline and follow-up outcomes as means and standard deviations. We used analysis of covariance to compare outcomes between groups at 17 weeks adjusting for baseline scores. Results are reported as both a mean between-group difference and Cohen's $d$ effect size each with $95 \%$ CIs. We examined the effect of missing data by imputing missing follow-up data using chained equations (White et al. 2011) incorporating data for all relevant variables. We then used the imputed dataset (using 30 imputations) to compare groups taking account of the multiply imputed data (White et al. 2011). We used procedures of Jacobson \& Truax (1991) for calculating reliable and clinically significant change to quantify clinical improvement in depressive symptoms on the EPDS (Matthey, 2004). Statistical analyses were performed using SPSS v. 18 (IBM, USA) and Stata v. 12 (StataCorp LP, USA).

The study was reviewed and received ethical approval from the University of Exeter ethics review committee.

\section{Results}

\section{Recruitment and attrition}

Fig. 1 presents the CONSORT (CONsolidated Standards of Reporting Trials) diagram showing the flow of participants through the trial. Demographic characteristics are given in Table 2. Of the 249 women who expressed initial interest in the trial, we randomized 83 women (33\%): 41 to NetmumsHWD and 42 to TAU. Post-treatment EPDS was completed by $37 / 41(90 \%)$ women in the NetmumsHWD condition and by $34 / 42$ (81\%) women in the TAU group $\left(\chi^{2}=1.45, p=0.23\right)$. A 6 -month follow-up EPDS was completed by $31 / 41 \quad(76 \%)$ women in the NetmumsHWD group and 28/41 (68\%) women in the TAU group $\left(\chi^{2}=0.37, p=0.47\right)$. There were no differences between those who expressed an interest in the trial, were randomized, completed the post-treatment or 6-month follow-up assessment measures and those who did not on baseline measures of psychological functioning or by sociodemographic characteristics.

\section{Treatment adherence}

Choice of optional modules was relatively evenly distributed across the different modules, although the most frequently chosen module was 'Being a good enough mother' (22\%, $n=18 / 82$; denominator $82=$ possible module choices $=41$ women in treatment $\times$ two module choices). Women viewed a mean of 6.74 (S.D. $=4.53)$ computer sessions and completed 5.36 (S.D. $=4.62)$. A total of 11 women $(5 \%)$ completed 


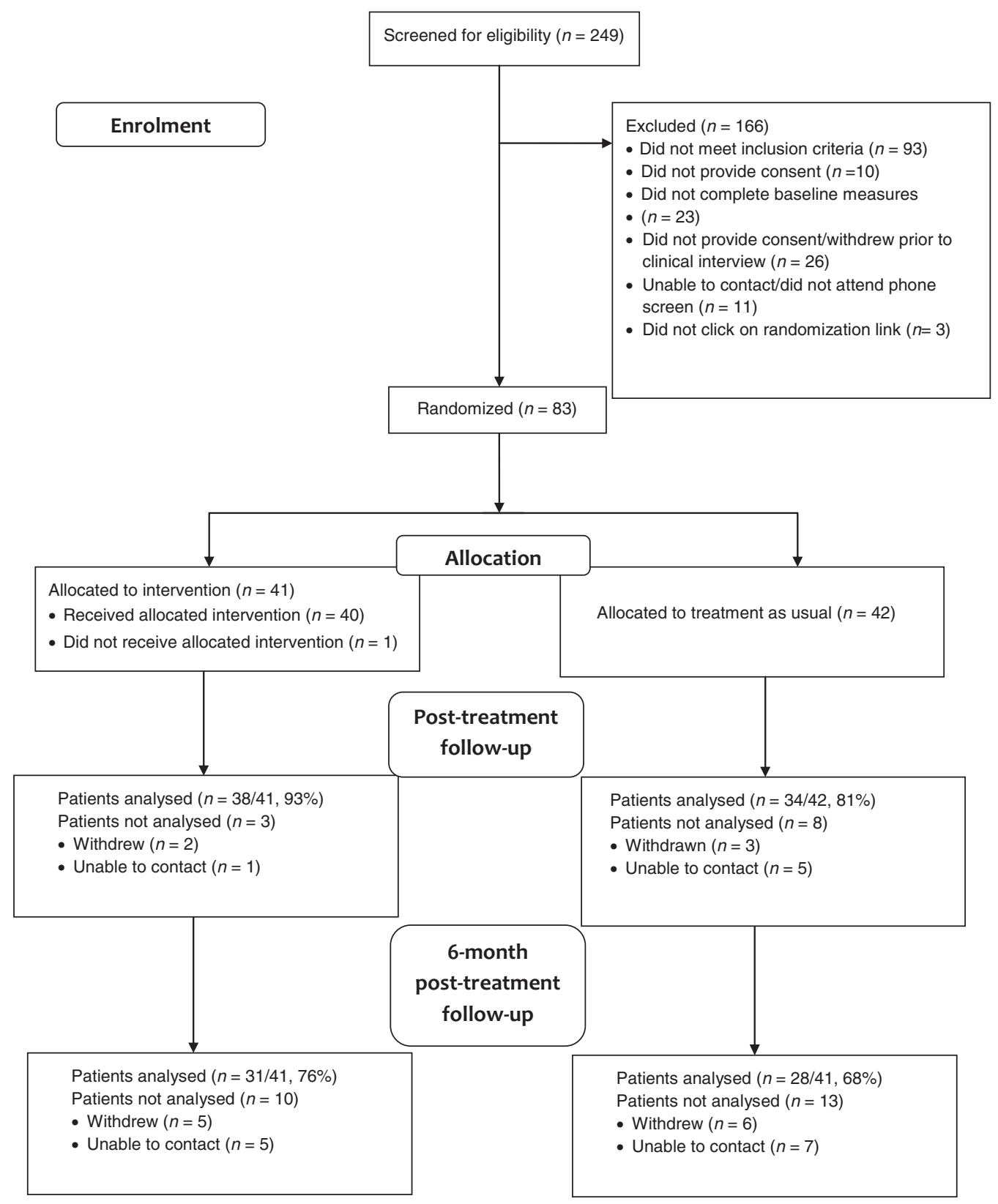

Fig. 1. CONSORT 2010 flow diagram.

eight or more computer sessions. Of these, five (1.9\%) women completed 12 computer sessions. The mean number of completed telephone support sessions was eight (S.D.=4.5, mode=12). Telephone session 1 had a mean duration of $50 \mathrm{~min}$ (S.D. $=4.31$ ), and sessions 2-12 had a mean duration of $29 \mathrm{~min}$ (S.D. $=4.76$ ). The average total time of sessions per participant was $253 \mathrm{~min}$. See Fig. 2 for detailed frequencies of number of telephone support and Internet modules completed. Although unexpected missed appointments were infrequent (mean=0.35, S.D. $=0.63$ ), patient appointment cancellations and rescheduling were more common, and were typically communicated via text or email (mean $n=1.65$, s.D. $=0.78$ ). Of four women who discontinued treatment and provided reasons for doing so, two reported they did not have enough time, one stated she was overwhelmed, and one reported feeling better.

\section{Predictors of treatment adherence}

Participants were from a wide socio-economic and demographic range (Table 3), with high levels of depressive symptoms [EPDS mean for intervention 20.24 (S.D.=3.28); TAU 21.07 (S.D. =4.0)] and functional impairment [mean WASAS for intervention 
Table 2. Characteristics of participants at baseline

\begin{tabular}{|c|c|c|}
\hline Baseline characteristic & NetmumsHWD & TAU \\
\hline \multicolumn{3}{|l|}{ Income, $n(\%)$} \\
\hline$<£ 10000$ & $4(9.2)$ & $2(4.8)$ \\
\hline$£ 10000-£ 19000$ & $6(14.6)$ & $10(23.8)$ \\
\hline$£ 20000-£ 29999$ & $6(14.6)$ & $4(9.5)$ \\
\hline$£ 30000-£ 39999$ & $5(12.2)$ & $10(23.8)$ \\
\hline$£ 40000-£ 49999$ & $4(9.8)$ & $7(16.7)$ \\
\hline$£ 50000-£ 59999$ & $6(14.6)$ & $2(4.8)$ \\
\hline$£ 60000-£ 69999$ & $7(17.1)$ & $3(7.1)$ \\
\hline$£ 70000-£ 79999$ & $2(4.9)$ & $3(7.1)$ \\
\hline$\geqslant £ 80000$ & - & $1(2.4)$ \\
\hline \multicolumn{3}{|l|}{ Work status, $n(\%)$} \\
\hline Homemaker/maternity leave/disability & $32(80.5)$ & $32(80.5)$ \\
\hline Full- or part-time employment & $3(7.3)$ & $6(14.3)$ \\
\hline Student or volunteer & $3(7.3)$ & $4(9.6)$ \\
\hline \multicolumn{3}{|l|}{ Relationship status, $n(\%)$} \\
\hline Married/cohabiting & $38(92.6)$ & $38(90.5)$ \\
\hline Not in a relationship now & $3(7.3)$ & $4(9.5)$ \\
\hline \multicolumn{3}{|l|}{ Academic qualifications, $n(\%)$} \\
\hline None & $1(2.4)$ & N.A. \\
\hline Secondary & $4(9.7)$ & $11(26.2)$ \\
\hline Post-16 years & $13(31.7)$ & $10(23.8)$ \\
\hline Undergraduate degree & $13(31.7)$ & $12(28.6)$ \\
\hline Graduate degree & $10(24.4)$ & $9(21.4)$ \\
\hline \multicolumn{3}{|l|}{ Number of children, $n(\%)$} \\
\hline 1 & $19(46.3)$ & $16(38.1)$ \\
\hline 2 & $18(43.9)$ & $16(38.1)$ \\
\hline 3 & $1(2.4)$ & $9(21.4)$ \\
\hline 4 or more & $3(7.6)$ & $1(2.4)$ \\
\hline \multicolumn{3}{|l|}{ Ethnic group, $n(\%)$} \\
\hline White/British & $38(92.6)$ & $39(92.9)$ \\
\hline Asian & $1(2.4)$ & N.A. \\
\hline Mixed white/African/Caribbean & N.A. & $2(4.8)$ \\
\hline African & N.A. & $1(2.4)$ \\
\hline Other & $2(4.8)$ & N.A. \\
\hline
\end{tabular}

NetmumsHWD, Netmums Helping With Depression; TAU, treatment as usual; N.A., not applicable.

29.8 (S.D.=7.8); TAU 28.8 (S.D.=9.1)]. Table 3 shows analysis of predictors of treatment adherence. There were no predictors of number of telephone sessions completed. Women with lower perceived support and who were working or studying for a degree completed fewer modules. Lastly, women with poorer WASAS baseline functioning and who were of a lower socioeconomic status (SES) opened fewer sessions than women with higher functioning or SES level.

\section{Symptoms of depression, anxiety and social adjustment}

Mean differences and between-subject effect sizes for the symptom measures are shown in Table 4.
There was a between-group difference in EPDS and GAD-7 scores for the observed data analysis at posttreatment favouring the NetmumsHWD group. These differences in the observed results correspond to large Cohen's $d$ effect sizes of EPDS $(-0.87,95 \% \mathrm{CI}$ -0.42 to -1.32$)$ and GAD-7 $(-0.59,95 \% \mathrm{CI}-1.11$ to $-0.07)$. There was also a between-group difference in the observed WASAS scores favouring the NetmumsHWD group corresponding to a moderate effect size $(-0.57,95 \% \mathrm{CI}-0.07$ to 1.11$)$. There were no between-group differences in postnatal selfreported bonding or perceived support scores between women in the NetmumsHWD group and those in the TAU group, reflecting a small $(0.29,95 \% \mathrm{CI}-0.80$ to $-0.22)$ and medium $(0.50,95 \%$ CI 1.02 to -0.02$)$ effect 
Table 3. Predictors of treatment adherence

\begin{tabular}{|c|c|c|c|c|c|c|c|c|}
\hline \multirow[b]{2}{*}{ Factor } & \multicolumn{2}{|l|}{ Trial adherence } & \multicolumn{2}{|c|}{ Telephone sessions } & \multicolumn{2}{|c|}{ Modules completed } & \multicolumn{2}{|l|}{ Modules opened } \\
\hline & Test statistic: $t$ & $p$ & $\begin{array}{l}\text { Test statistic: } r \\
\text { correlation }\end{array}$ & $p$ & $\begin{array}{l}\text { Test statistic: } r \\
\text { correlation }\end{array}$ & $p$ & $\begin{array}{l}\text { Test statistic: } r \\
\text { correlation }\end{array}$ & $p$ \\
\hline EPDS & -0.59 & 0.56 & -0.01 & 0.94 & -0.26 & 0.10 & 0.20 & 0.41 \\
\hline GAD-7 & -0.53 & 0.60 & -0.16 & 0.35 & 0.00 & 0.98 & 0.20 & 0.20 \\
\hline WASAS & -0.44 & 0.67 & -0.28 & 0.09 & -0.15 & 0.35 & 0.66 & 0.01 \\
\hline SPS & -10.32 & 0.34 & -0.01 & 0.96 & 0.33 & 0.04 & 0.16 & 0.49 \\
\hline PBQ & -10.64 & 0.52 & 0.11 & 0.51 & 0.07 & 0.67 & 0.38 & 0.10 \\
\hline \multirow[t]{2}{*}{ Income level } & Eta & 0.12 & -0.01 & 0.97 & -0.52 & 0.02 & -0.52 & 0.02 \\
\hline & & & $\begin{array}{l}\text { Goodman \& } \\
\text { Kruskal lambda }\end{array}$ & & $\begin{array}{l}\text { Goodman \& } \\
\text { Kruskal lambda }\end{array}$ & & $\begin{array}{l}\text { Goodman \& } \\
\text { Kruskal lambda }\end{array}$ & \\
\hline Academic qualification & -0.65 & 0.52 & 0.05 & 0.86 & 0.22 & 0.16 & 0.08 & 0.70 \\
\hline Relationship status & 0.20 & 0.35 & 0.04 & 0.31 & 0.09 & 0.26 & 0.08 & 0.65 \\
\hline Number of children & -0.58 & 0.11 & 0.26 & 0.12 & 0.27 & 0.45 & 0.09 & 0.31 \\
\hline Work status & 0.07 & 0.95 & 0.17 & 0.17 & 0.22 & 0.04 & 0.23 & 0.24 \\
\hline
\end{tabular}

EPDS, Edinburgh Postnatal Depression Scale; GAD-7, Generalized Anxiety Disorder Screener; WASAS, Work and Social Adjustment Scale; SPS, Social Provision Scale; PBQ, Postnatal Bonding Questionnaire.

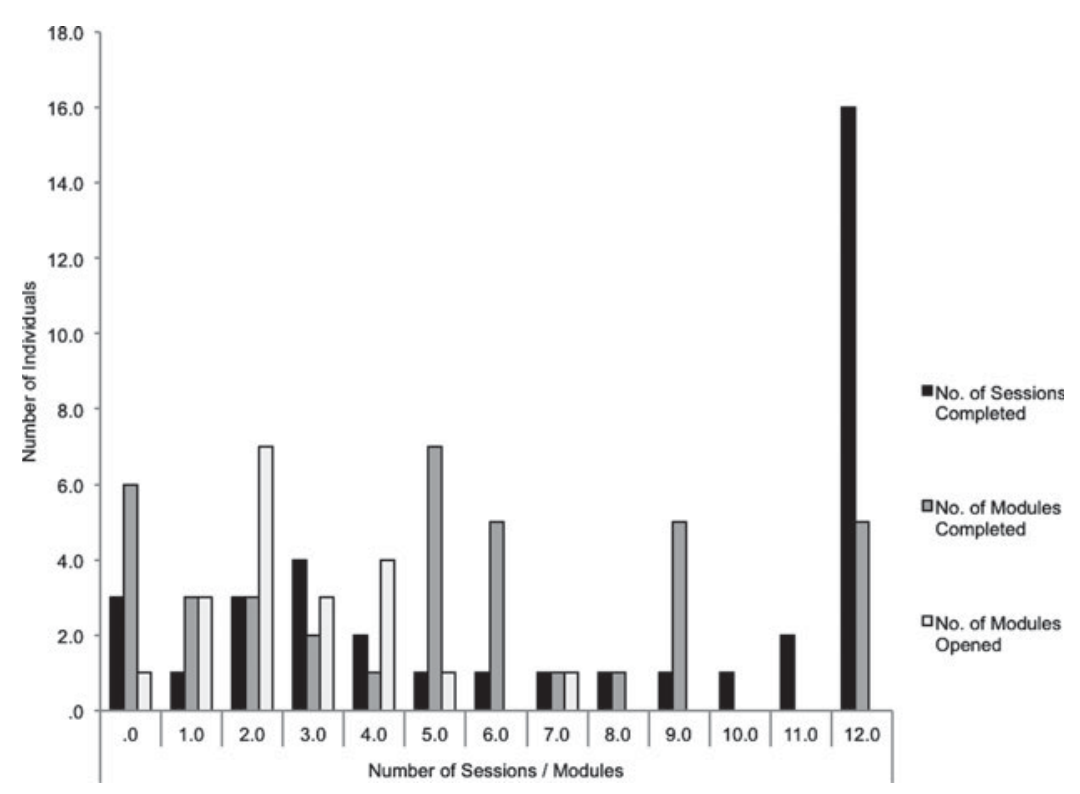

Fig. 2. Frequencies of the number of sessions/modules completed or opened.

size, respectively. In the multiple imputation sensitivity analyses, EPDS, GAD-7 and WASAS scores at 17 weeks post-randomization remained in favour of NetmumsHWD. At 6 months post-treatment followup, there was a trend favouring NetmumsHWD $($ mean $=8.26$, S.D. $=5.50)$ over TAU $($ mean $=11.14$, S.D. $=6.35$; mean difference -2.69 , 95\% CI -5.80 to $-0.42)$, corresponding to a large effect size $(-0.78$, $95 \%$ CI -1.82 to 0.10$)$. This was replicated in the multiple imputation sensitivity analysis (mean difference $-2.28,95 \% \mathrm{CI}-5.41$ to 0.84 ), corresponding to a large effect size $(-0.678,95 \% \mathrm{CI}-1.121$ to -0.236$)$.

\section{Reliable and clinically significant improvement}

A reliable and clinically significant improvement in depression scores was seen in $62.2 \%(n=23 / 37)$ of those in the NetmumsHWD group at post-treatment 


\begin{tabular}{|c|c|c|c|c|c|c|c|c|}
\hline \multirow[b]{2}{*}{ Condition } & \multirow[b]{2}{*}{ Measurement } & \multicolumn{2}{|l|}{ Pre-treatment } & \multicolumn{2}{|c|}{$\begin{array}{l}17 \text {-week } \\
\text { post-randomization }\end{array}$} & \multirow{2}{*}{$\begin{array}{l}\text { Between-group difference } \\
\text { Mean }(95 \% \text { CI })\end{array}$} & \multirow[b]{2}{*}{$p$} & \multirow{2}{*}{$\begin{array}{l}\text { Effect size } \\
\text { Cohen's } d(95 \% \mathrm{CI})\end{array}$} \\
\hline & & Mean (S.D.) & $n$ & Mean (S.D.) & $n$ & & & \\
\hline $\begin{array}{l}\text { Intervention } \\
\text { Control }\end{array}$ & EPDS & $\begin{array}{l}20.24(3.28) \\
21.07(4.0)\end{array}$ & $\begin{array}{l}41 \\
42\end{array}$ & $\begin{array}{l}11.05(4.71) \\
14.26(5.11)\end{array}$ & $\begin{array}{l}37 \\
34\end{array}$ & $\begin{array}{l}-3.02(-5.34 \text { to }-0.70) \\
\text { Imputed }-3.26(-5.57 \text { to }-0.95)\end{array}$ & $\begin{array}{l}0.01 \\
\text { Imputed }<0.01\end{array}$ & $\begin{array}{l}-0.87(-1.32 \text { to }-0.42) \\
\text { Imputed }-0.960(-1.415 \text { to }-0.505)\end{array}$ \\
\hline $\begin{array}{l}\text { Intervention } \\
\text { Control }\end{array}$ & GAD-7 & $\begin{array}{l}13.90(3.82) \\
14.12(4.78)\end{array}$ & $\begin{array}{l}41 \\
42\end{array}$ & $\begin{array}{l}8.71(4.61) \\
11.29(5.49)\end{array}$ & $\begin{array}{l}31 \\
28\end{array}$ & $\begin{array}{l}-2.74(-5.19 \text { to }-0.30) \\
\text { Imputed }-2.73(-4.98 \text { to }-0.49)\end{array}$ & $\begin{array}{l}0.03 \\
\text { Imputed } 0.02\end{array}$ & $\begin{array}{l}-0.59(-1.11 \text { to } 0.07) \\
\text { Imputed }-0.655(-1.097 \text { to }-0.213)\end{array}$ \\
\hline $\begin{array}{l}\text { Intervention } \\
\text { Control }\end{array}$ & WASAS & $\begin{array}{l}19.24(4.90) \\
19.64(6.10)\end{array}$ & $\begin{array}{l}41 \\
42\end{array}$ & $\begin{array}{l}13.13(6.70) \\
17.18(7.25)\end{array}$ & $\begin{array}{l}31 \\
28\end{array}$ & $\begin{array}{l}-3.67(-7.61 \text { to }-0.17) \\
\text { Imputed }-4.01(-7.24 \text { to }-0.78)\end{array}$ & $\begin{array}{l}0.04 \\
\text { Imputed } 0.02\end{array}$ & $\begin{array}{l}-0.57(1.10 \text { to }-0.06) \\
\text { Imputed }-0.756(1.202 \text { to }-0.310)\end{array}$ \\
\hline $\begin{array}{l}\text { Intervention } \\
\text { Control }\end{array}$ & PBQ & $\begin{array}{l}31.66(15.74) \\
24.93(18.72)\end{array}$ & $\begin{array}{l}41 \\
42\end{array}$ & $\begin{array}{l}22.57(12.99) \\
17.57(11.17)\end{array}$ & $\begin{array}{l}31 \\
28\end{array}$ & $\begin{array}{l}1.42(-4.32 \text { to } 7.16) \\
\text { Imputed } 1.18(-4.77 \text { to } 7.13)\end{array}$ & $\begin{array}{l}0.62 \\
\text { Imputed } 0.69\end{array}$ & $\begin{array}{l}0.29(0.22 \text { to } 0.80) \\
\text { Imputed } 0.247(-0.185 \text { to } 0.679)\end{array}$ \\
\hline $\begin{array}{l}\text { Intervention } \\
\text { Control }\end{array}$ & SPS & $\begin{array}{l}67.61(9.71) \\
67.36(10.89)\end{array}$ & $\begin{array}{l}41 \\
42\end{array}$ & $\begin{array}{l}73.63(9.83) \\
68.39(10.49)\end{array}$ & $\begin{array}{l}31 \\
28\end{array}$ & $\begin{array}{l}2.28(-1.79 \text { to } 2.03) \\
\text { Imputed } 2.44(-1.62 \text { to } 6.51)\end{array}$ & $\begin{array}{l}0.27 \\
\text { Imputed } 0.23\end{array}$ & $\begin{array}{l}0.50(-0.02 \text { to } 1.02) \\
\text { Imputed } 0.25(-0.179 \text { to } 0.686)\end{array}$ \\
\hline
\end{tabular}

S.D., Standard deviation; CI, confidence interval; EPDS, Edinburgh Postnatal Depression Scale; GAD-7, Generalized Anxiety Disorder Screener; WASAS, Work and Social Adjustment Scale; SPS, Social Provision Scale; PBQ, Postnatal Bonding Questionnaire.

* Difference in post-treatment (completer) score between groups adjusting for pre-treatment score. 
Table 5. Health service utilization at baseline a and 17-week follow-up by treatment condition

\begin{tabular}{|c|c|c|c|c|c|}
\hline & \multicolumn{2}{|c|}{ NetmumsHWD } & \multicolumn{2}{|l|}{ TAU } & \multirow[b]{2}{*}{$p$} \\
\hline & Mean (S.D.) & $n(\%)$ & Mean (S.D.) & $n(\%)$ & \\
\hline \multicolumn{6}{|l|}{ Childbirth hospital } \\
\hline Baseline & $1.81(3.40)$ & $16 / 41(39)$ & $1.31(4.46)$ & $8 / 42(19)$ & 0.57 \\
\hline 17-week follow-up & $0.10(0.62)$ & $1 / 30(2.4)$ & $0.64(3.11)$ & $2 / 27(7.4)$ & 0.28 \\
\hline \multicolumn{6}{|c|}{ Maternal general health hospital } \\
\hline Baseline & $0.05(0.22)$ & 2/41 (4.9) & $0.17(0.66)$ & $4 / 42(9.5)$ & 0.28 \\
\hline 17-week follow-up & 0 & $0 / 30$ & 0 & $0 / 27$ & N.A. \\
\hline \multicolumn{6}{|l|}{ Infant hospital } \\
\hline Baseline & $1.17(3.26)$ & $12 / 41(29.3)$ & $0.88(2.01)$ & $11 / 42(26.2)$ & 0.63 \\
\hline 17-week follow-up & $0.24(0.99)$ & $4 / 30(13.3)$ & $0.38(1.35)$ & $6 / 27(22.2)$ & 0.60 \\
\hline \multicolumn{6}{|l|}{ Mental health hospital } \\
\hline Baseline & 0 & $0 / 41$ & $0.05(0.31)$ & $1 / 42(2.4)$ & 0.11 \\
\hline 17-week follow-up & 0 & $0 / 30$ & $0.05(0.31)$ & $1 / 27(2.4)$ & 0.33 \\
\hline \multicolumn{6}{|c|}{ Mental health out-patient ${ }^{b}$} \\
\hline Baseline & $1.68(4.57)$ & $15 / 41(36.6)$ & $1.02(3.02)$ & $10 / 42(37)$ & 0.44 \\
\hline 17-week follow-up & $5.07(3.34)$ & $14 / 30(46.7)$ & $10.37(15.76)$ & $11 / 27(40.7)$ & 0.23 \\
\hline \multicolumn{6}{|c|}{ Health community service } \\
\hline Baseline & $7.51(7.89)$ & $39 / 41(95.1)$ & $6.95(6.25)$ & $40 / 42(95.2)$ & 0.72 \\
\hline 17-week follow-up & $3.32(3.94)$ & $28 / 30(93.3)$ & $2.95(3.31)$ & $25 / 27(92.6)$ & 0.65 \\
\hline \multicolumn{6}{|c|}{ Antidepressant medication } \\
\hline Baseline & $2.95(0.77)$ & $27 / 41(65.9)$ & $3.07(0.75)$ & $23 / 42(59.5)$ & 0.47 \\
\hline 17-week follow-up & $2.96(0.76)$ & $19 / 27(70.4)$ & $3.07(0.75)$ & $19 / 30(63.3)$ & 0.38 \\
\hline
\end{tabular}

NetmumsHWD, Netmums Helping With Depression; TAU, treatment as usual; s.D., standard deviation; N.A., not applicable.

${ }^{a}$ Health care utilization at baseline assessed use in the previous 6 months.

${ }^{\mathrm{b}}$ Mental health utilization was in the 6 months previously. Women were excluded from the trial if they were currently receiving mental health therapy.

compared with $29.4 \%(n=10 / 34)$ of those in the TAU group. After adjustment for baseline EPDS the odds ratio for a reliable and clinically significant improvement in the treatment group compared with control was 0.26 (95\% CI $0.10-0.71)$.

\section{Health service utilization}

Health service utilization is presented in Table 5 . There were no differences in utilization between the NetmumsHWD and TAU groups at baseline or at follow up. At baseline, 63\% (52/83) of the total randomized sample was taking an antidepressant medication, and although none of the women randomized were currently in psychological treatment for depression, $37 \%(25 / 83)$ had received an average of 1.34 (S.D. $=3.85)$ sessions of out-patient treatment in the previous 3 months.

\section{Discussion}

We found that we were able to recruit and retain sufficient participants to the study and that the supported NetmumsHWD programme had high levels of trial and clinical adherence, demonstrating promise as a feasible treatment for PND. The between-group effect size of the NetmumsHWD programme was large $(-0.87,95 \%$ CI $0.42-1.32)$, and the effects were reliably and clinically significant for over $60 \%$ of users. Although the $95 \%$ CI was wide, spanning a medium to very large effect size, these results compare favourably with effect sizes from meta-analyses of faceto-face treatments for PND $(-0.65,95 \%$ CI -0.45 to -0.86; Sockol et al. 2011) and with online CBT treatments for MDD that provide an element of guided support (0.61, 95\% CI 0.45-0.77; Andersson \& Cuijpers, 2009), including a recent trial of guided online CBT for general maternal depression (Sheeber et al. 2012). These results suggest that the NetmumsHWD programme is feasible, and may offer promise as an effective treatment for PND. As the NetmumsHWD programme requires minimal therapist time (average session time was $29 \mathrm{~min}$; average total time of sessions per participant was $253 \mathrm{~min}$ ), it may offer a costeffective and accessible treatment option for PND.

We recruited and randomized $33 \%$ of women who expressed interest in the study. We would therefore expect similar rates of recruitment in a future trial. We retained $83 \%$ of women in the trial at 
post-treatment follow-up and 71\% at 6-month followup, although it was more difficult to retain women in the TAU condition. These short-term attrition rates compare favourably with other face-to-face and online treatment trials (Kaltenthaler et al. 2008; Christensen et al. 2009; Andrews et al. 2010). Further qualitative work with women in this study may highlight modifiable factors contributing to attrition. However, we note that these trial attrition rates compare very favourably with another recent online trial of BA for PND that did not include telephone guidance (O'Mahen et al. $2013 b)$. In that trial, we retained $38 \%(n=343 / 910)$ of women, a rate consistent with other unsupported, online treatment trials (Etter, 2005; Farvolden et al. 2005; Christensen et al. 2009). Women completed an average of five Internet sessions (s.D. =4.76) and a mode of 12 telephone sessions. Many women began to incorporate content from the optional modules when they worked on their first functional analysis and alternate plan in the initial core sessions. Although the Internet sessions were designed to be completed in 1 week, there was considerable variability amongst women in the number of weeks it took them to complete each Internet session. Having a higher income, being on maternity leave or not working, having higher perceived social support, and better social and occupational functioning at baseline were related with opening and completing more modules. Women with complex life circumstances required more time to work through materials, and supporters helped them to appropriately pace and utilize the treatment content. Overall, the higher rates of treatment and trial adherence retention we achieved with guided support in this trial are in line with a growing body of research demonstrating that the provision of guidance in online treatments enhances treatment uptake and retention (Cuijpers et al. 2010).

The results suggest that NetmumsHWD offers promise in improving functioning and reducing anxiety relative to women on TAU. The effect sizes were moderate in size. Although there was a trend in the NetmumsHWD programme towards improved perceived support and maternal self-reported bonding with infant, the effect sizes were small. In all analyses, the CIs were wide, which we would expect in a sample of this size. The broader literature in this area suggests that women with support and/or bonding problems may require specific interventions directed at remediating these difficulties (Poobalan et al. 2007). Furthermore, because previous research has demonstrated that not all mothers with PND experience bonding difficulties with their infants (Tharner et al. 2012), it may be important to direct specific interventions only to those mothers who are experiencing difficulties. A larger, definitive trial would permit examinations of whether the modules on communication and parenting are helpful for women experiencing difficulties in these specific domains.

\section{Implications}

The results from this trial suggest that the provision of guidance in an Internet-based treatment for PND is associated with less trial and treatment attrition. The intention-to-treat imputed effect sizes of the NetmumsHWD intervention contrasted with TAU are comparable with the intention-to-treat effects for completers only in a previous unsupported trial of this intervention ( $\mathrm{O}^{\prime}$ Mahen et al. 2013b), but the key difference in this trial is that we had considerably less attrition. Importantly, results from the previous trial of PND and other studies of unsupported online treatments (Christensen et al. 2004, 2009; O'Mahen et al. 2013b) suggest that some individuals do not require guidance to persist with treatment. Our preliminary findings from this study also point to subgroups of individuals who may require more support. Research investigating psychological and sociodemographic factors associated with treatment adherence may support stratified, nuanced treatments that personalize levels of support.

Further, it is unclear from the results in the current trial whether the effect of the intervention was due to the computer content itself, the telephone-based support, or an interaction of the two. Multifactorial designs comparing unsupported and supported versions of the treatment may help to explicate the active components of the interventions.

\section{Limitations}

A large-scale examination of a guidance-based version of the NetmumsHWD treatment is needed to definitively assess its efficacy and cost-effectiveness. Future research would benefit from longer-term follow-up, clinical interview assessment of mood at post-treatment, and observational assessments of mother-child interaction. Internet treatments may serve as a treatment endpoint, or may be a starting point leading to further treatment. For example, we noted that some women in treatment also struggled with post-traumatic stress disorder and grief, in addition to MDD, and some initiated new treatments focused on their co-morbidities alongside NetmumsHWD. It is important to demonstrate how the cost of Internet treatment fares relative to other treatment provision. A large-scale trial would also allow for the examination of definitive predictors of treatment adherence. Based on the baseline and post-17-week correlations and minimum clinically important difference data from the larger literature, 
the sample size calculations for a larger trial would range from 69 per group, when using a power of $80 \%$ and $20 \%$ attrition, to 132 per group when using $90 \%$ power and $30 \%$ attrition. Lastly, it is important to note that Internet interventions may not be appropriate for all individuals. For example, users of the current trial were all Netmums users who may have found Internet approaches more acceptable.

\section{Conclusion}

Our study adds to a growing body of literature that has demonstrated the feasibility and clinical utility of Internet interventions for depression. To our knowledge, this is the first RCT demonstrating the clinical potential of a supported online intervention specifically developed for PND. Such an intervention may hold promise for reaching groups of women who do not have local access to empirically supported treatments, struggle with issues of stigma, or have a particular need for flexibility and in-home treatment delivery (Kaltenthaler et al. 2006).

\section{Notes}

1 All effect sizes reported are either Cohen's $d$ or Hedges' $g$. Hedges' $g$ is comparably similar to Cohen's $d$ but includes statistical adjustments for small sample size (Rosenthal \& Rosnow, 2008).

\section{Acknowledgements}

We are grateful to the women who participated in this research. Naomi Gilbert, Sally Piper and Emma Seaman provided valuable service user input into the development of the intervention. Mary Duggan contributed to the development of the intervention and provided specialist support to the chat room during the course of the trial. Sally Russell and Netmums.com have lent their support and encouragement throughout the development and completion of this research. Netmums' commitment to helping mothers has made this work possible. Ed Watkins graciously allowed us to adapt his rumination-focused treatment strategies featured in the rumination module. We acknowledge funding from the National Institute for Health Research (NIHR) Collaboration for Leadership in Applied Health Research and Care (CLAHRC) for the South West Peninsula. The views expressed in this publication are those of the author(s) and not necessarily those of the National Health Service (NHS), the NIHR or the Department of Health in England.

\section{Declaration of Interest}

None.

\section{References}

Addis ME, Martell CR (2004). Overcoming Depression One Step at a Time: The New Behavioral Activation Approach to Getting Your Life Back. New Harbinger Press: New York.

Andersson G, Cuijpers P (2009). Internet-based and other computerized psychological treatments for adult depression: a meta-analysis. Cognitive Behaviour Therapy 38, 196-205.

Andrews G, Cuijpers P, Craske MG, McEvoy P, Titov N (2010). Computer therapy for the anxiety and depressive disorders is effective, acceptable and practical health care: a meta-analysis. PLoS One 5, e13196.

Beattie A, Shaw A, Kaur S, Kessler D (2009). Primary-care patients' expectations and experiences of online cognitive behavioral therapy for depression: a qualitative study. Health Expectations 12, 45-59.

Brockington F, Oates J, Georges S, Turner D, Vostanis P, Sullivan M, Lohr C, Murdoh C (2001). A screening questionnaire for mother-infant bonding disorders. Archives of Women's Mental Health 3, 133-140.

Buist A, Bilszta J, Barnett B, Milgrom J, Ericksen J, Condon J, Hayes B, Brooks J (2005). Recognition and management of perinatal depression in general practice. Australian Family Physician 34, 787-790.

Byford S, McCrone P, Barrett B (2003). Developments in the quantity and quality of economic evaluations in mental health. Current Opinion in Psychiatry 16, 703-707.

Christensen H, Griffiths KM, Farrer L (2009). Adherence in Internet interventions for anxiety and depression: a systematic review. Journal of Medical Internet Research 11, e13.

Christensen H, Griffiths KM, Jorm AF (2004). Delivering interventions for depression by using the Internet: randomised controlled trial. British Medical Journal 328, 265.

Cox JL, Holden JM, Sagovsky R (1987). Detection of postnatal depression. Development of the 10-item Edinburgh Postnatal Depression Scale. British Journal of Psychiatry 150, 782-786.

Craig P, Dieppe P, Macintyre S, Michie S, Nazareth I, Petticrew M (2008). Developing and evaluating complex interventions: the new Medical Research Council guidance. British Medical Journal 337, a1655.

Crisp A, Gelder M, Goddard E, Meltzer H (2005). Stigmatization of people with mental illnesses: a follow-up study within the Changing Minds campaign of the Royal College of Psychiatrists. World Psychiatry 4, 106-113.

Cuijpers P, Donker T, van Straten A, Li J, Andersson G (2010). Is guided self-help as effective as face-to-face psychotherapy for depression and anxiety disorders? A systematic review and meta-analysis of comparative outcome studies. Psychological Medicine 40, 1943-1957.

Cutrona CE, Russell D (1987). The provisions of social relationships and adaptation to stress. In Advances in Personal Relationships, vol. 1 (ed. H. Jones and D. Perlman), pp. 37-67. JAI Press: Greenwich, CT.

Dennis C-L, Chung-Lee L (2006). Postpartum depression help-seeking barriers and maternal treatment preferences: a qualitative systematic review. Birth 33, 323-331. 
Dimidjian S, Hollon SD, Dobson KS, Schmaling KB, Kohlenberg RJ, Addis ME, Gallop R, McGlinchey JB, Markley DK, Gollan JK, Atkins DC, Dunner DL, Jacobson NS (2006). Randomized trial of behavioral activation, cognitive therapy, and antidepressant medication in the acute treatment of adults with major depression. Journal of Consulting and Clinical Psychology 74, 658-670.

Etter JF (2005). Comparing the efficacy of two Internet-based, computer-tailored smoking cessation programs: a randomized trial. Journal of Medical and Internet Research 7, e2.

Farvolden P, Denisoff E, Selby P, Bagby RM, Rudy L (2005). Usage and longitudinal effectiveness of a web-based self-help cognitive behavioral therapy program for panic disorder. Journal of Medical and Internet Research 7, e7.

Gavin NI, Gaynes BN, Lohr KN, Meltzer-Brody S, Gartlhner G, Swinson T (2005). Perinatal depression: a systematic review of prevalence and incidence. Obstetrics and Gynecology 106, 1071-1083.

Goodman JH (2009). Women's attitudes, preferences, and perceived barriers to treatment for perinatal depression. Birth 36, 60-69.

Hind D, O'Cathain A, Cooper CL, Parry GD, Isaac CL, Rose A, Martin L, Sharrack B (2009). The acceptability of computerized cognitive behavioral therapy for the treatment of depression in people with chronic physical disease: a qualitative study of people with multiple sclerosis. Psychology and Health 25, 699-712.

Jacobson NS, Martell CR, Dimidjian S (2001). Behavioral activation treatment for depression: returning to contextual roots. Clinical Psychology: Science and Practice 8, 255-270.

Jacobson NS, Truax P (1991). Clinical significance: a statistical approach to defining meaningful change in psychotherapy research. Journal of Consulting and Clinical Psychology 59, 12-19.

Julious SA (2005). Sample size of 12 per group rule of thumb for a pilot study. Pharmaceutical Statistics 4, 287-291.

Kaltenthaler E, Brazier J, De Nigris E, Tumur I, Ferriter M, Beverley C, Parry G, Rooney G, Sutcliffe P (2006). Computerised cognitive behaviour therapy for depression and anxiety update: a systematic review and economic evaluation. Health Technology Assessment 10, 1-168.

Kaltenthaler E, Parry G, Beverley C, Ferriter M (2008). Computerised cognitive-behavioral therapy for depression: systematic review. British Journal of Psychiatry 193, 181-184.

Kohn R, Saxena S, Levav I, Saraceno B (2004). The treatment gap in mental health care. Bulletin of the World Health Organization 82, 858-866.

Le H-N, Perry DF, Sheng X (2009). Using the Internet to screen for postpartum depression. Maternal and Child Health Journal 13, 213-221.

Löwe B, Decker O, Müller S, Brähler E, Schellberg D, Herzog W, Herzberg PY (2008). Validation and standardization of the Generalized Anxiety Disorder Screener (GAD-7) in the general population. Medical Care 46, 266-274.

Matthey S (2004). Calculating clinically significant change in postnatal depression studies using the Edinburgh
Postnatal Depression Scale. Journal of Affective Disorders 78, 269-272.

Meyer B, Berger T, Caspar F, Beevers CG, Andersson G, Weiss M (2009). Effectiveness of a novel integrative online treatment for depression (Deprexis): randomized controlled trial. Journal of Medical Internet Research 11, e15.

Mundt JC, Marks IM, Greist JH, Shear K (2002). The Work and Social Adjustment Scale: a simple accurate measure of impairment in functioning. British Journal of Psychiatry 180, 461-464.

Murray L, Arteche A, Fearon P, Halligan S, Croudace T, Cooper P (2010). The effects of maternal postnatal depression and child sex on academic performance at age 16 years: a developmental approach. Journal of Child Psychology and Psychiatry 51, 1150-1159.

Murray L, Woolgar M, Cooper P (2004). Detection and treatment of postpartum depression. Community Practitioner 77, 13-17.

National Institute for Health and Clinical Excellence (2007). Antenatal and Postnatal Mental Health. National Institute for Health and Clinical Excellence: London.

National Research Council and Institute of Medicine (2009). Depression in Parents, Parenting, and Children: Opportunities to Improve Identification, Treatment, and Prevention. Committee on Depression, Parenting Practices, and the Healthy Development of Children. Board on Children, Youth, and Families. Division of Behavioral and Social Sciences and Education. The National Academies Press: Washington, DC.

O'Mahen HA, Fedock G, Henshaw E, Himle J, Forman J, Flynn HA (2012). Modifying CBT for perinatal depression: what do women want? A qualitative study. Cognitive and Behavioral Practice 19, 359-371.

O'Mahen HA, Flynn HA (2008). Preferences and perceived barriers to treatment for depression during the perinatal period. Journal of Women's Health 17, 1301-1309.

O'Mahen HA, Himle J, Fedock G, Henshaw E, Flynn HA (2013a). A pilot randomized controlled trial of cognitive behavioral therapy for perinatal depression for women with low income. Depression and Anxiety 30, 679-687.

O'Mahen HA, Woodford J, McKinley J, Taylor R, Lynch T, Warren F (2013b). A randomized controlled trial of an unsupported Internet-based behavioral activation treatment for postnatal depression: a feasibility study. Journal of Affective Disorders. Published online: 17 April 2013. doi:10.1016/j.jad.2013.03.005.

Pawlby S, Sharp D, Hay D, O'Keane V (2008). Postnatal depression and child outcome at 11 years: the importance of accurate diagnosis. Journal of Affective Disorders 107, 241-245.

Payne KA, Myhr G (2010). Increasing access to cognitivebehavioral therapy (CBT) for the treatment of mental illness in Canada: a research framework and call for action. Health Care Policy 5, e173-e175.

Perini S, Titov N, Andrews G (2009). Clinician-assisted Internet-based treatment is effective for depression: randomized controlled trial. Australian and New Zealand Journal of Psychiatry 43, 571-578. 
Poobalan AS, Aucott LS, Ross L, Smith WC, Helms PJ, Williams JH (2007). Effects of treating postnatal depression on mother-infant interaction and child development: systematic review. British Journal of Psychiatry 191, 378-386.

Reay R, Fisher Y, Robertson M, Adams E, Owen C, Kumar R (2006). Group interpersonal psychotherapy for postnatal depression: a pilot study. Archives of Women's Mental Health 9, 31-39.

Rosenthal R, Rosnow RL (2008). Essentials of Behavioral Research: Methods and Data Analysis, 3rd edn. McGraw-Hill: New York.

Sheeber LB, Seeley JR, Feil EG, Davis B, Sorensen E, Kosty DB, Lewinsohn PM (2012). Development and pilot evaluation of an internet-facilitated cognitive-behavioural intervention for maternal depression. Journal of Consulting and Clinical Psychology 80, 739-749.

Sockol LE, Epperson CN, Barber JP (2011). A meta-analysis of treatments for perinatal depression. Clinical Psychology Review 31, 839-849.

Spek V, Cuijpers P, Nyklíček Riper H, Keyzer J, Pop V (2007). Internet-based cognitive behaviour therapy for symptoms of depression and anxiety: a meta-analysis. Psychological Medicine 37, 319-328.

Spitzer RL, Kroenke K, Williams JBW, Löwe B (2006). A brief measure for assessing generalized anxiety disorder: the GAD-7. Archives of Internal Medicine 166, 1092-1097.

Swinson RP (2006). The GAD-7 scale was accurate for diagnosing generalized anxiety disorder. Evidence Based Medicine 11, 184.

Tharner A, Lujik MP, van Ijzendoorn MH, Bakermans-Kranenburg MJ, Jaddoe VW, Hofman A, Verhulst FC, Tiemejer H (2012). Maternal lifetime history of depression and depressive symptoms in the prenatal and early postnatal period do not predict infant-mother attachment quality in a large, population-based Dutch cohort study. Attachment and Human Development 14, 63-81.

Warmerdam L, van Straten A, Twisk J, Riper H, Cuijpers $P$ (2008). Internet-based treatment for adults with depressive symptoms: randomized controlled trial. Journal of Medical Internet Research 10, e44.

White IR, Royston P, Wood AM (2011). Multiple imputation using chained equations: issues and guidance for practice. Statistics in Medicine 30, 377-399. 